\title{
Immediate extinction causes a less durable loss of performance than delayed extinction following either fear or appetitive conditioning
}

\author{
Amanda M. Woods and Mark E. Bouton ${ }^{1}$ \\ Department of Psychology, University of Vermont, Burlington, Vermont 05405, USA
}

\begin{abstract}
Five experiments with rat subjects compared the effects of immediate and delayed extinction on the durability of extinction learning. Three experiments examined extinction of fear conditioning (using the conditioned emotional response method), and two experiments examined extinction of appetitive conditioning (using the food-cup entry method). In all experiments, conditioning and extinction were accomplished in single sessions, and retention testing took place $24 \mathrm{~h}$ after extinction. In both fear and appetitive conditioning, immediate extinction (beginning 10 min after conditioning) caused a faster loss of responding than delayed extinction (beginning $24 \mathrm{~h}$ after conditioning). However, immediate extinction was less durable than delayed extinction: There was stronger spontaneous recovery during the final retention test. There was also substantial renewal of responding when the physical context was changed between immediate extinction and testing (Experiment 1). The results suggest that, in these two widely used conditioning preparations, immediate extinction does not erase or depotentiate the original learning, and instead creates a less permanent reduction in conditioned responding. Results did not support the possibility that the strong recovery after immediate extinction was due to a mismatch in the recent "context" provided by the presence or absence of a recent conditioning experience. Several other accounts are considered.
\end{abstract}

In classical conditioning, extinction is the procedure by which the conditioned stimulus (CS) is presented without the unconditioned stimulus (US), and the conditioned response diminishes as a result (Pavlov 1927). Extinction is thought to be the basis of exposure therapy, a common treatment involving controlled exposure to a fear-eliciting stimulus (e.g., Barlow 1988; Bouton 1988; Davis and Myers, 2002). Research on extinction therefore has important implications for the treatment of fear and anxiety disorders in humans. One theoretical approach to extinction assumes that it might cause unlearning or erasure of original learning (Rescorla and Wagner 1972). However, extensive behavioral evidence shows that the conditioned response can reappear under various conditions after extinction (see Bouton 2004). Such research indicates that extinction does not destroy original learning. As a result, the organism remains vulnerable to lapse and relapse after extinction (e.g., Bouton et al. 2006a).

The renewal effect, one type of relapse often observed in the laboratory, occurs when the CS (e.g., a light) is presented outside the extinction context (e.g., Bouton and Bolles 1979a). "Context" can include any physical (e.g., apparatus, location, odors) or temporal stimuli as well as internal states (e.g., hormonal or drug state) and emotions (see Bouton 2002). Renewal indicates that extinction is specific to the context in which it occurs (see also Harris et al. 2000). Another type of relapse, spontaneous recovery, occurs as time passes after extinction (i.e., when the temporal context changes (e.g., Brooks and Bouton 1993; see also Pavlov 1927; Rescorla 2004a). Reinstatement refers to the return of conditioned responding to the CS that occurs when the US (e.g., shock) is presented alone after extinction (e.g., Rescorla and Heth 1975; Bouton and Bolles 1979b; see also Westbrook et al. 2002). It is mediated by conditioning of the context (e.g., Bouton and Bolles 1979b; Bouton 1984): US-alone presentations are associated with the context, and this context conditioning triggers

'Corresponding author.

E-mail Mark.bouton@uvm.edu; fax (802) 656-8783.

Article is online at http://www.learnmem.org/cgi/doi/10.1101//m.1078508. fear of the extinguished CS when the CS is later tested in the same context (i.e., reinstatement is context-specific). A fourth example of relapse is rapid reacquisition in which the conditioned response rapidly returns when CS-US pairings are resumed after extinction (e.g., Napier et al. 1992; Ricker and Bouton 1996). Each of these phenomena indicates that extinction does not destroy the original learning. Therefore, many current theories propose that extinction involves the formation of new, inhibitory learning that merely suppresses original learning (e.g., Pearce and Hall 1980; Wagner 1981; Bouton 1993, 2004). Bouton (1993, 2004) has emphasized the view that extinction depends on new learning that is especially dependent on the context for retrieval.

In addition to the behavioral data, research on the neurobiology of learning and memory provides evidence that extinction involves new learning. For example, $N$-methyl- $D$-aspartate (NMDA) receptors in the amygdala are necessary for fear conditioning, as well as extinction (e.g., Falls et al. 1992; see Walker and Davis 2002, for a review). NMDA receptors have been implicated in several forms of learning and in long-term potentiation (LTP), a synaptic model of learning (Whitlock et al. 2006; see also Fanselow 1993). The fact that extinction, like initial conditioning, at least partially depends on NMDA receptors suggests that it too involves new learning. Additional neurobiological evidence reveals further similarities in the mechanisms of conditioning and extinction (see e.g., Myers and Davis 2002). For example, both involve modulation of second messenger systems (e.g., Lu et al. 2001; Lin et al. 2003b; Szapiro et al. 2003) and require protein synthesis (Vianna et al. 2001; Santini et al. 2004; cf. Lattal and Abel 2001).

The finding that an NMDA receptor antagonist, such as APV, blocks extinction (e.g., Falls et al. 1992) led Walker et al. (2002) to propose that an agonist should facilitate extinction. D-cycloserine (DCS), a partial agonist of the NMDA receptor, does increase the rate of extinction (e.g., Walker et al. 2002; Ledgerwood et al. 2003). DCS has also enhanced the effectiveness of exposure therapy for several anxiety disorders in humans (e.g., 
Ressler et al. 2004; Kushner et al. 2007; Guastella et al. 2008). Despite its short-term benefits on extinction performance, however, DCS does not necessarily lead to the erasure of the original learning. For example, although DCS speeds extinction, it does not prevent the renewal effect when rats are tested outside the extinction context (Woods and Bouton 2006). Thus, the organism might remain vulnerable to lapse and relapse under some conditions (see Morris and Bouton [2007], for a related discussion of yohimbine, and alpha- 2 adrenergic autoreceptor antagonist).

Despite numerous observations of relapse, new neurobiological data suggest that original learning, as manifested in LTP, might actually be unlearned or erased under some other conditions. In particular, Gean and colleagues have shown that LTP in amygdala slices can subsequently be reversed through synaptic depotentiation, a process that can be induced by low-frequency stimulation (Lin et al. 2003a; see also Aroniadou-Anderjaska et al. 2001). Depotentiation counteracts most of the effects of LTP, including protein synthesis and phosphorylation of second messenger cascades leading to gene transcription (see e.g., Lin et al. 2003a, 2005). Depotentiation is generally inducible only within intervals less than $1 \mathrm{~h}$ after LTP induction (e.g., Stäubli and Chun 1996; Huang et al. 2001). Under such conditions, synaptic potentiation (LTP) returns to baseline; this suggests the memory trace might have been erased. When depotentiation is induced in the amygdala in vivo $10 \mathrm{~min}$ after fear conditioning, it blocks the expression of fear $24 \mathrm{~h}$ later (Lin et al. 2003a). Thus, like extinction, depotentiation eliminates the conditioned response.

The procedures used by Gean and colleagues typically involved generating depotentiation soon (i.e., $10 \mathrm{~min}$ ) after LTP induction. The idea that depotentiation might underlie extinction and cause erasure of original learning recently led Myers et al. (2006) to hypothesize that giving extinction soon after fear conditioning should thwart relapse. They conducted a series of experiments in the fear-potentiated startle paradigm with rats in which the interval between conditioning and extinction was manipulated. When extinction began $72 \mathrm{~h}$ after conditioning, the rats subsequently demonstrated reinstatement (Experiment 1), renewal (Experiment 2), and spontaneous recovery (Experiment 3) of the conditioned response. This result was not surprising given that most research on relapse effects in the behavioral literature typically involves at least a 24 -h interval between the end of conditioning and the beginning of extinction (e.g., Bouton et al. 2006b). The important new result, however, was that when extinction began $10 \mathrm{~min}$ after conditioning, the rats did not demonstrate any of these examples of relapse.

The results of Myers et al. (2006) suggest that extinction initiated immediately (i.e., within $1 \mathrm{~h}$ ) after conditioning might invoke depotentiation and cause erasure of the original memory. Despite the promise of these findings, there is reason to ask whether they are general. First, other experiments have provided evidence of relapse effects even after immediate extinction. For example, using the skin conductance response (SCR) as a measure of fear conditioning, LaBar and Phelps (2005) demonstrated reinstatement after extinction in human participants that had received extinction immediately after CS-US pairings (see also Hermans et al. 2005; Dirikx et al. 2007). Using a similar method, Schiller et al. (2008) replicated the reinstatement effect and further reported spontaneous recovery of the SCR when participants were tested $24 \mathrm{~h}$ after immediate extinction. In addition, in fearconditioning experiments with rats, Schiller et al. (2008) reported reinstatement and spontaneous recovery of conditioned freezing after both immediate and delayed extinction (which had occurred $12 \mathrm{~min}$ or $3 \mathrm{~d}$ after acquisition, respectively); the amount of relapse did not differ statistically between the extinction conditions. Milad et al. (2005) observed renewal of the SCR in humans that received immediate extinction and were then tested outside the extinction context. Likewise, Alvarez et al. (2007) reported renewal of SCR, fear ratings, and even fearpotentiated startle in humans returned to the fear-conditioning context after receiving immediate extinction in a different context.

Additional behavioral research examining the conditioningextinction interval is also inconsistent with the findings of Myers et al. (2006). Maren and Chang (2006) reported that rats given extinction immediately (15 $\mathrm{min})$ after acquisition of conditioned freezing showed poorer retention of extinction (i.e., more freezing) during testing than those given extinction after a 24-h delay. Also, in appetitive conditioning with both rats and pigeons, Rescorla (2004b) reported greater spontaneous recovery when extinction began after a short $(1 \mathrm{~d})$ rather than a long $(9 \mathrm{~d})$ interval following conditioning. Both of these reports suggest that under some conditions, delayed extinction produces better, rather than worse, long-term retention of extinction.

The present experiments further compared the effects of immediate and delayed extinction in two widely used aversive and appetitive-conditioning preparations in rats. The first three experiments employed the conditioned emotional response (CER) method (Estes and Skinner 1941), in which a CS is paired with shock, and the index of fear conditioning is the ability of the CS to suppress an ongoing operant baseline reinforced by food. This method has a long history in the study of fear conditioning (e.g., Annau and Kamin 1961; Rescorla 1968; Kamin 1969; Randich and Rescorla 1981; Bouton and King 1983). Experiments 4 and 5 used an appetitive-conditioning preparation in which the CS was paired with food pellets and conditioning was indexed by the number of times the rat inspected the food cup (e.g., Lattal 1999; Bouton and Sunsay 2003; Rescorla 2004b, 2006; Morris and Bouton 2006).

\section{Results}

\section{Fear conditioning}

\section{Experiment 1: Spontaneous recovery and renewal after immediate and delayed extinction}

The first experiment compared the effects of immediate and delayed extinction in the CER preparation. Four groups received fear conditioning in a single session in one context (Context A). They then received extinction in Context $\mathrm{B}$ beginning either 10 min or $24 \mathrm{~h}$ later. (Extinction was conducted in a context differ-

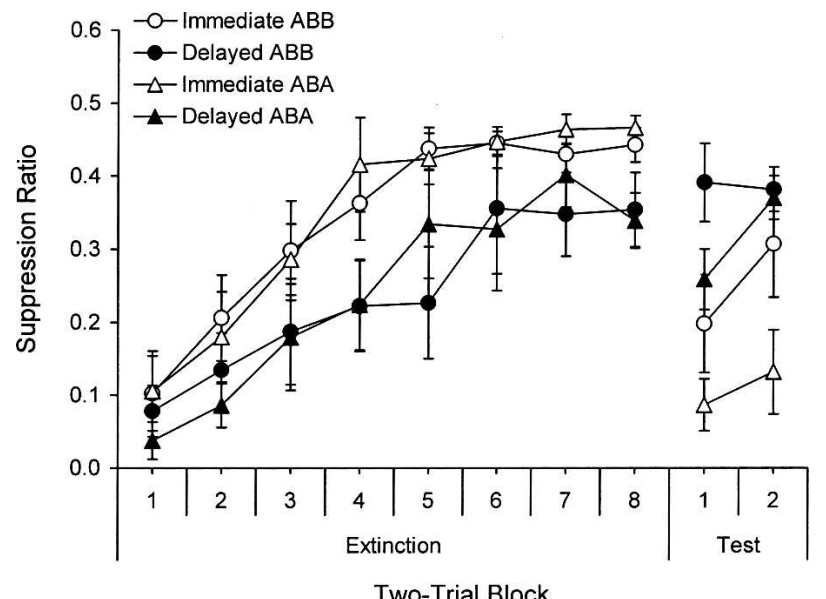

Figure 1. Mean suppression ratios ( \pm SE) over two-trial blocks from the extinction session in Context B and the test session in Context A or B in Experiment 1. 


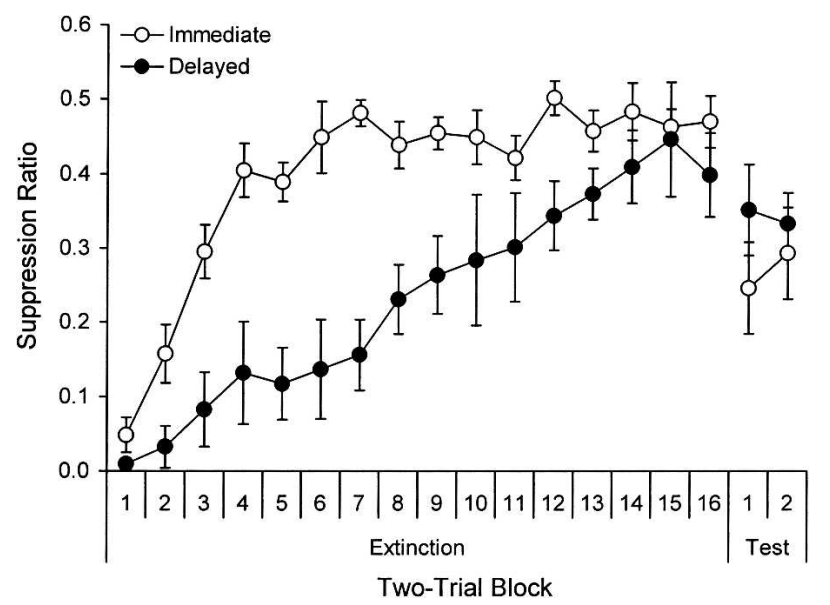

Figure 2. Mean suppression ratios ( \pm SE) over two-trial blocks from the extinction and test sessions in Context B in Experiment 2.

ent from the fear conditioning context to minimize complications caused by losing the operant baseline, which was expected to occur in the conditioning context because of contextual conditioning.) Twenty-four hours after extinction, the groups received tests of the CS. One group from each of the conditions was tested in Context B, the extinction context; and the other group was tested in Context A, the conditioning context. A renewal of suppression would ordinarily be expected when the CS is returned to Context A.

The results are presented in Figure 1, which shows suppression to the CS over two-trial blocks from the extinction session in Context B and the test session in either Context A or B. The $y$-axis shows the suppression ratio, the standard dependent measure used in this preparation. A suppression ratio of 0 indicates maximal suppression (fear of the CS), whereas a ratio of 0.5 indicates no suppression. As the figure suggests, extinction was faster when it followed conditioning immediately. A 2 (Interval) $\times 2$ (Context) $\times 8$ (Block) ANOVA on the eight two-trial blocks from this session confirmed main effects of Block, $F_{(7,196)}=34.67$, and Interval, $F_{(1,28)}=8.83$. There was no main effect of Context (a dummy variable at this point), $F_{(1,28)}<1$, and no interactions, $F$ s $\leq 1.35$. A 2 (Interval) $\times 2$ (Context) ANOVA on the last block revealed a main effect of Interval, $F_{(1,28)}=7.39$, indicating more fear at the end of extinction in the delayed groups. The effect of Context and the interaction were not reliable, $F \mathrm{~s}_{(1,28)}<1$.

The right-hand side of Figure 1 depicts the data from the test session conducted $24 \mathrm{~h}$ after extinction. Immediate extinction did not prevent either renewal or spontaneous recovery of fear after extinction. Indeed, there was substantially more suppression following immediate than following delayed extinction. A 2 (Interval) $\times 2$ (Context, i.e., whether or not there was a context switch between extinction and testing) $\times 2$ (Block) ANOVA comparing the last two-trial block of extinction with the first two-trial block of the test confirmed a main effect of Block, $F_{(1,24)}=36.98$, and Context effect that fell just short of the $P<0.05$ rejection criterion, $F_{(1,24)}=3.36, P=0.079$. Importantly, there was a Block $\times$ Interval interaction, $F_{(1,24)}=28.29$, indicating a greater increase in suppression in the immediate-extinction groups. The Block $\times$ Context interaction was also reliable, $F_{(1,24)}=5.18$, indicating a stronger increase in suppression to the $\mathrm{CS}$ between extinction and testing in rats that were returned to Context A during the test (the renewal effect). The main effect of Interval, $F_{(1,24)}=1.31$, the Interval $\times$ Context, and the three-way interaction were not reliable, $F s<1$. Simple effects tests were performed. When the immediate-extinction groups were isolated, there was a main effect of Block, $F_{(1,13)}=63.46$, but no effect of Context and no Block $\times$ Context interaction, $F \mathrm{~s}_{(1,13)} \leq 2.94$, suggesting a return of fear in both test contexts after immediate extinction. In contrast, when the delayed-extinction groups were isolated, there were no main effects or interactions, $F \mathrm{~s}_{(1,11)} \leq 2.34$, suggesting that extinction performance was retained in both test contexts after delayed extinction. A $2 \times 2$ between-groups ANOVA isolating suppression on the first twotrial block of testing revealed a Context effect, $F_{(1,24)}=5.85$, which did not interact with Interval, $F_{(1,24)}<1$. The main effect of Interval was significant, $F_{(1,24)}=13.25$, which again indicates that the groups given immediate extinction exhibited more fear during testing than the groups given delayed extinction.

Lever-press rates during the 60-s interval before each CS (the "pre-CS period") were analyzed in parallel Interval $\times$ Context $\times$ Block ANOVAs. These revealed no group differences in pre-CS responding during either extinction, $F \mathrm{~s} \leq 1.08$, or testing, $F \mathrm{~s} \leq 1.53$, where pre-CS responding averaged 16.2 and 19.8 (responses/min), respectively. Furthermore, on the first twotrial block of extinction, there were no group differences, $F_{(1,24)}=2.04$ (the average pre-CS rate was 13.6); the lack of difference suggests the groups entered extinction with similar levels of contextual fear. There were also no differences on the first two-trial block of testing, $F \mathrm{~s}_{(1,24)}<1$, where the average rate was 19.0; because the groups exhibited similar levels of contextual fear on the test, that factor did not contribute to the different amounts of fear (relapse) that the groups exhibited to the CS.

Overall, the results suggest that, with the current method, immediate extinction caused a faster loss of suppression than extinction conducted $24 \mathrm{~h}$ after conditioning. This finding is consistent with other CER data showing that fear "incubates" as the delay between conditioning and extinction increases (McMichael 1966; Randich and Rescorla 1981). Immediate extinction has also been shown to proceed more quickly than delayed extinction in a conditioned freezing paradigm (Schiller et al. 2008; cf. Maren and Chang 2006). The more important result, however, is that immediate extinction did not prevent a return of fear after extinction. Instead, strong spontaneous recovery and renewal both occurred after immediate extinction, and the spontaneous recovery effect was notably stronger than that observed after delayed extinction. ${ }^{2}$

Experiment 2: Spontaneous recovery after extended immediate or delayed extinction

Because immediate extinction caused a quicker loss of suppression in Experiment 1, the groups that received immediate and delayed extinction entered the retention test at different points on the suppression ratio scale. The immediate-extinction group had more room on the response scale to show a strong return of fear. In the second experiment, we therefore gave Immediate and Delayed extinction groups twice the number of extinction trials (32 instead of 16) in order to allow behavior to converge. The results are presented in Figure 2. As before, extinction was faster when it followed conditioning immediately, but in this case the extra extinction trials allowed suppression of the two groups to come together by the end of the phase. A 2 (Interval) $\times 16$ (Block) ANOVA on the two-trial blocks of extinction confirmed main effects of Block, $F_{(15,210)}=19.28$, and Interval, $F_{(1,14)}=19.25$,

\footnotetext{
${ }^{2} \mathrm{~A}$ control experiment also found more spontaneous recovery following immediate than delayed extinction when the conditioning-to-test interval was controlled (A.M. Woods, unpubl.). Experiment 1, which instead controlled the extinction-to-test interval, provides a more compelling demonstration of the low durability of immediate extinction, because extinction performance is usually more readily lost over time than conditioning performance (e.g., Bouton 1993). When the conditioning-to-test interval is controlled, the extinction-totest interval testing is necessarily longer for immediate than delayed extinction.
} 
and a Block $\times$ Interval interaction, $F_{(15,210)}=3.04$. However, an ANOVA on the last block confirmed that the effect of Interval was no longer significant, $F_{(1,14)}=2.44$.

The results of the test session $24 \mathrm{~h}$ later are shown on the right in Figure 2. Even after double the number of extinction trials, rats given immediate extinction again exhibited stronger spontaneous recovery than those given delayed extinction. A 2 (Interval) $\times 2$ (Block) ANOVA comparing the last two-trial block of extinction with the first two-trial block of the test confirmed a main effect of Block, $F_{(1,13)}=6.89$. There was no effect of Interval, $F_{(1,13)}<1$. Although the Block $\times$ Interval interaction did not reach significance, $F_{(1,13)}=3.01$, simple effects tests isolating each group provided evidence of spontaneous recovery (i.e., a main effect of Block) in Group Immediate, $F_{(1,7)}=6.22$, but not in Group Delayed, $F_{(1,6)}=1.44$. A between-groups comparison of suppression on the first block of testing did not reveal a difference, $F_{(1,13)}=1.48$. However, the significant increase in fear between extinction and testing in the Immediate Group, and lack of effect in the Delayed Group, indicates that immediate extinction was less effective than delayed in preventing spontaneous recovery (the increase in conditioned responding that occurs as time elapses after extinction).

Parallel analyses of response rates during the pre-CS periods revealed no effects of Interval or interactions with Block, $F$ s $\leq 3.80$. Pre-CS response rates averaged 14.8 during extinction and 15.2 during testing overall. There were also no group differences on the first extinction two-trial block, $F_{(1,13)}<1$, where the average rate was 14.2 , or on the first two-trial block of the test, $F_{(1,13)}<1$, where the average rate was also 14.2 .

\section{Experiment 3: Testing the role of contextual mismatch}

One possible cause of the less durable effect of immediate extinction is that there was a greater mismatch between the contextual conditions prevailing during extinction and retention testing. For example, rats given immediate extinction could have been extinguished while still emotional from the preceding conditioning experience. When tested, however, there was no immediately preceding fear experience, and less emotion at the start of the test. The change in emotional context could have caused a renewal of suppression (e.g., Bouton 1993, 2002). Alternatively, the mere presence and then absence of a recent conditioning session in memory at the time of extinction and testing could provide contextual change. In contrast, the delayed-extinction groups received no context change between extinction and testing, making renewal less likely.

The third experiment was therefore designed to examine the role of contextual mismatch (e.g., Bouton 1993). We factorially introduced a fear-conditioning session with a different CS, a tone, before extinction and/or testing in different groups. Four groups received fear conditioning with the light-off CS on one day and then delayed extinction $24 \mathrm{~h}$ later. For two groups, extinction was like that received by the delayed-extinction groups in Experiment 1. However, the two remaining groups received a session of fear conditioning with the tone CS immediately before (delayed) extinction of the target CS. During testing $24 \mathrm{~h}$ after extinction, one group from each of the extinction conditions received the usual retention test with the light-off CS. The other groups received a session of fear conditioning with the tone immediately before the test. In this way, the presence or absence of the preceding tone conditioning session established a kind of context that was either matched or mismatched between extinction and testing. If the strong fear during testing in the previous immediate-extinction groups was due to contextual mismatch, then we should expect more test fear when there was a mismatch than when there was a match. To increase statistical power, we ran the experiment twice (in two replications), and thus doubled the usual number of subjects.

The extinction and test results with the target light-off CS are presented in Figure 3. Similar to immediate extinction, the loss of suppression to the light off was faster when extinction began $10 \mathrm{~min}$ after a fear conditioning experience (with the tone). A 2 (Ext) $\times 2$ (Test) $\times 2$ (Replication) $\times 8$ (Block) ANOVA on the eight two-trial blocks from this session confirmed a main effect of Block, $F_{(7,364)}=58.65$, and Extinction treatment, $F_{(1,52)}=4.87$. There was no effect of Test treatment (a dummy variable at this point) or Replication, and no interactions, $F$ s $\leq 1.14$. An ANOVA on the last block revealed that the effect of Extinction treatment was not significant, $F_{(1,52)}=3.32$. Overall, the similarity of the pattern to that observed in Experiments 1 and 2 is consistent with the hypothesis that the more rapid loss of suppression in immediate extinction is due to the persistence of some nonspecific effect of recent fear conditioning on extinction.

The right-hand side of Figure 3 depicts the data from testing $24 \mathrm{~h}$ later. There was no effect of the mismatch of the extinction and testing conditions. Instead, all groups showed apparently equivalent spontaneous recovery of fear to the light-off CS. A 2 (Ext) $\times 2$ (Test) $\times 2$ (Replication) $\times 2$ (Block) ANOVA comparing the last two-trial block of extinction with the first two-trial block of the test confirmed a main effect of Block, $F_{(1,41)}=45.69$. There was a main effect of Extinction treatment, $F_{(1,41)}=6.47$, likely because the groups that received an extra conditioning session before extinction exhibited less suppression than the other groups on the final extinction block. There was also a main effect of Replication, $F_{(1,41)}=4.88$; the groups exhibited less suppression in Replication 2. There was no effect of Test treatment, $F_{(1,41)}<1$. But most important, the Block $\times$ Extinction treatment, the Block $\times$ Test treatment, the Extinction $\times$ Test treatment, and the Block $\times$ Extinction $\times$ Test treatment interactions all failed to reach significance, $F \mathrm{~s}_{(1,41)} \leq 1.18$. There were no interactions with Replication, $F \mathrm{~s}_{(1,41)} \leq 3.55$. Simple effects tests isolating each group further confirmed a main effect of Block in all groups, $F \mathrm{~s} \geq 9.20$. A $2 \times 2 \times 2$ ANOVA isolating suppression on the first two-trial block of testing further confirmed a lack of difference among the groups, $F \mathrm{~s}_{(1,41)} \leq 1.57$. The results are not consistent with the contextual mismatch hypothesis.

Parallel analyses of the pre-CS data revealed no main effects of the group factors or interactions during extinction, $F \mathrm{~s} \leq 1.25$, where pre-CS responses per minute averaged 16.4. There were also no group differences in pre-CS responding on the first ex-

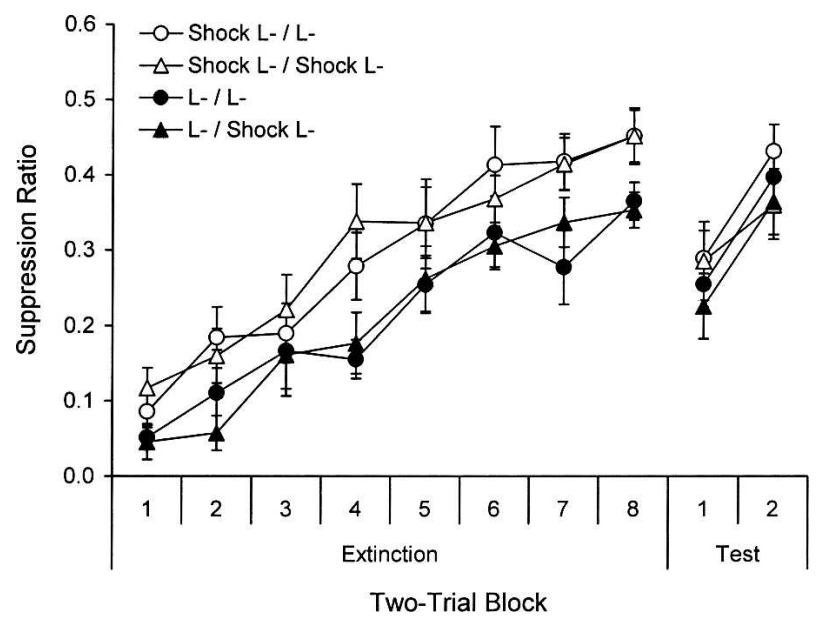

Figure 3. Mean suppression ratios $( \pm \mathrm{SE}$ ) over two-trial blocks from the extinction and test sessions in Context B in Experiment 3. 
tinction two-trial block, $F_{(1,41)} \leq 1.05$, where the average rate was 14.7. A parallel ANOVA on the pre-CS data of testing revealed that most effects did not approach significance, $F \mathrm{~s}_{(1,48)} \leq 1.60$. The exception was the Block $\times$ Test treatment interaction, $F_{(1,41)}=5.28$, which suggests that the groups that received a tone conditioning session immediately before the test exhibited a slight decrease in pre-CS responding from extinction to the test, whereas the other two groups exhibited a slight increase. Pre-CS responses per minute on the last two-trial block of extinction were 17.9, 17.4, 17.8, and 20.2 for Groups Shock L-/L-, Shock L-/Shock L-, L-/L-, and L-/Shock L-; on the first two-trial block of the test, the respective scores were 19.7, 15.0, 21.3, and 16.4 (there were again no group differences when this test block was isolated, $\left.F \mathrm{~s}_{(1,41)} \leq 3.85\right)$. Such small changes in baseline responding do not complicate interpretation of the suppression ratios.

The finding that recent fear conditioning with a second CS caused less suppression during extinction is consistent with data showing that fear incubation over a 24 -h interval can be reduced by presentation of the US or CS-US pairings (Randich and Rescorla 1981). Once again, the results are consistent with what is known about fear and its incubation in the CER situation.

Experiments 1-3 consistently found evidence of an incubation of CS fear when extinction was delayed by $24 \mathrm{~h}$ after a shock experience. (It is worth noting that, as reported above, there were no corresponding differences in the pre-CS baseline leverpressing rates when analyzed throughout the extinction sessions, or when analyzed on only the first two-trial block.) The incubation effect observed with the present method is consistent with the results reported in the freezing preparation by Schiller et al. (2008), but it contrasts with the conditioned freezing results reported by Maren and Chang (2006). The latter investigators found more (not less) freezing during extinction that immediately followed conditioning or presentation of unsignaled shock in a different context. The results led Maren and Chang (2006) to propose that a high level of fear around the time of extinction might cause poor long-term retention of extinction (recall that, like us, they found that immediate extinction caused less durable loss of fear than delayed extinction). However, the fact that we observed a similar result concerning the durability of extinction, but less (rather than more) fear of the CS during immediate extinction, suggests that the level of fear during extinction is not the factor controlling durability. The reason for why Maren and Chang's freezing was higher, whereas our conditioned suppression was lower, during immediate extinction or after shocking in another context is not clear at the present time. However, Maren and Chang's results are consistent with the possibility that the freezing response might have unusual temporal characteristics. For example, McNally and Westbrook (2006) reported more rapid acquisition of freezing when successive pairings of a chamber and shock were separated by short $(2 \mathrm{~min})$ intertrial intervals than by long (e.g., $24 \mathrm{~h}$ ) intervals. Such a result is consistent with Maren and Chang's finding that a CS presented immediately after conditioning yielded stronger freezing than a CS presented after a delay (cf. Schiller et al. 2008). But it contrasts with the typical result in most aversive and appetitive-conditioning procedures, where conditioning trials that are massed together in time usually yield slower acquisition of responding than trials that are more spaced (e.g., Spence and Norris 1950; Rescorla and Durlach 1987; Sunsay et al. 2004). It is important to reiterate that Maren and Chang (2006) found results consistent with ours concerning the lack of durability of immediate extinction. The contrast thus suggests that this result does not depend on either higher or lower fear during immediate extinction.

The second major result of Experiment 3, of course, is that regardless of whether a conditioning session preceded extinction and/or testing, rats in the four groups exhibited statistically in- distinguishable amounts of spontaneous recovery. Despite the fact that the tone-conditioning treatment was salient enough to have an impact on the animals' behaviors, as indicated by suppression during extinction, the level of final suppression to the target CS did not depend on the match or mismatch of the conditioning treatment that immediately preceded extinction and testing. The results thus did not confirm the contextual mismatch explanation (e.g., Bouton 1993) of the strong suppression observed during retention testing after immediate extinction in Experiments 1 and 2.

\section{Appetitive conditioning}

\section{Experiment 4: Spontaneous recovery after immediate and delayed extinction}

In order to develop an understanding of the results, it is important to know whether they are unique to fear conditioning. We therefore moved to a completely different motivational system and ran parallel experiments in a widely used appetitiveconditioning preparation in which the CS is paired with food pellets and the conditioned response is activity directed at the food cup in anticipation of the US. Historically, our laboratory has found many parallels between results obtained in fear and appetitive conditioning (e.g., Bouton 1993; Morris and Bouton 2006). And as noted above, Rescorla (2004b) reported results from appetitive-conditioning experiments with rats and pigeons that are consistent with the present results; there was more spontaneous recovery following immediate than delayed extinction. However, unlike Myers et al. (2006), Rescorla used a procedure that involved multiple conditioning sessions over several days, which gave the subjects multiple opportunities to consolidate conditioning before extinction. In addition, the shortest interval between conditioning and extinction was $24 \mathrm{~h}$ (Rescorla compared 1-d and 9-d intervals), a period of time that Myers et al. (2006) would have considered delayed extinction. We therefore examined the durability of immediate versus delayed extinction in an appetitive-conditioning experiment that, like the fear experiments, contained only a single conditioning session and included an immediate-extinction condition in which extinction began 10 min later.

As in our CER experiments, rats received conditioning (tone-food pairings) in a single session (Context A), and then received extinction in a different context (Context B) either 10 min or $24 \mathrm{~h}$ later. Testing then occurred $24 \mathrm{~h}$ after extinction.

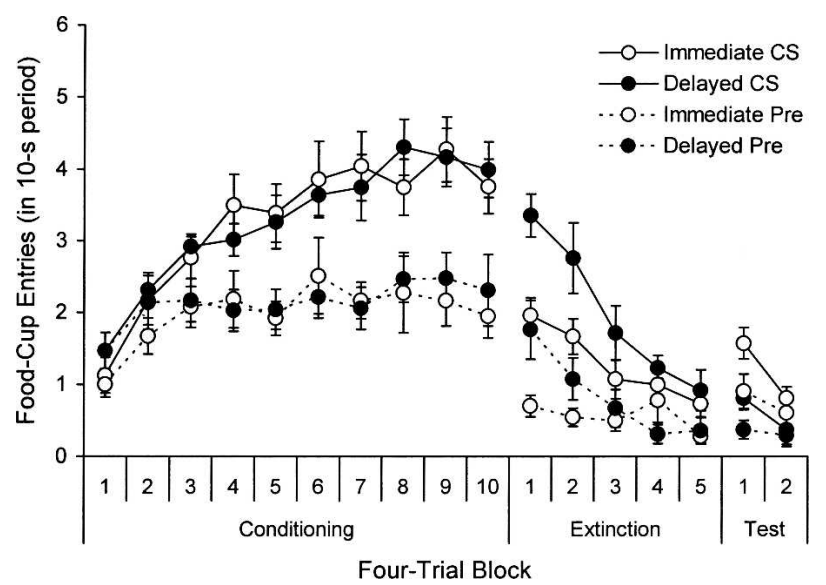

Figure 4. Mean number of food-cup entries ( \pm SE) during the 10-s CS and the equivalent 10-s period before the CS over four-trial blocks from the conditioning session in Context $\mathrm{A}$ and the extinction and test sessions in Context B in Experiment 4. 
The experiment was run in two replications. The results are shown in Figure 4, which presents the number of food-cup entries during the CS and the equivalent 10-s period immediately before the CS over four-trial blocks in conditioning, extinction, and testing. As the left side of the figure suggests, both groups acquired food-cup responding to the CS during conditioning. A 2 (Interval) $\times 2$ (Replication) $\times 10$ (Block) ANOVA on CS responding in this session confirmed a main effect of Block, $F_{(9,252)}=20.21$. No other main effects or interactions were reliable, Fs $<1$. A comparison of CS and pre-CS responding on the last block confirmed significantly higher responding to the CS within each group, $t s_{(15)} \geq 3.40$. A parallel ANOVA on the pre-CS data revealed a similar main effect of Block, $F_{(9,252)}=2.35$, confirming (as the figure shows) an increase in pre-CS responding during conditioning. This result is consistent with the possibility that the context, in addition to the CS itself, became associated with food during conditioning. There was also a main effect of Replication, $F_{(1,28)}=5.10$, due to higher pre-CS responding in Replication 2. The effect of Interval and the interactions were not reliable, $F \mathrm{~s} \leq 1.37$.

As the middle of the figure illustrates, extinction of food-cup responding was faster when it was immediate rather than delayed. A 2 (Interval) $\times 2$ (Replication) $\times 5$ (Block) ANOVA on CS responding during the five four-trial blocks from this session confirmed the main effects of Block, $F_{(4,112)}=21.85$, and Interval, $F_{(1,28)}=6.23$, and a significant Block $\times$ Interval interaction, $F_{(4,112)}=2.56$. There was also a main effect of Replication, $F_{(1,28)}=4.79$, due to higher responding in Replication 2 . The other interactions were not significant, $F \mathrm{~s}<1$. A 2 (Interval) $\times 2$ (Replication) ANOVA on the last block revealed that the main effect of Interval was no longer significant, $F_{(1,28)}<1$. Thus, the groups had converged to a similar point on the scale by the end of extinction. The main effect of Replication remained, $F_{(1,28)}=5.52$, but the interaction was not significant, $F_{(1,28)}<1$. A parallel $2 \times 2 \times 5$ ANOVA on the pre-CS data revealed that responding during the pre-CS period (in response to the context) also declined. There was a main effect of Block, $F_{(4,112)}=4.71$ and a Block $\times$ Interval interaction, $F_{(4,112)}=3.17$. The main effect of Replication approached significance, $F_{(1,28)}=3.98, P=0.056$ (again due to higher pre-CS responding in Replication 2). The effect of Interval and the other interactions were not reliable, $F$ s $\leq 3.21$. An additional ANOVA revealed that the immediate group responded less than the delayed group in the pre-CS period on the first extinction block, $F_{(1,28)}=5.48$.

Results from the test session (right side of the figure) suggest that immediate extinction once again did not prevent spontaneous recovery. Instead, as before, rats given immediate extinction actually exhibited more recovery of responding than rats given delayed extinction. A 2 (Interval) $\times 2$ (Replication) $\times 2$ (Block) ANOVA comparing CS responding on the last four-trial block of extinction and the first four-trial block of the test confirmed a main effect of Block, $F_{(1,28)}=3.91, P=0.058$, and importantly, a significant Block $\times$ Interval interaction, $F_{(1,28)}=6.59$. There was also a main effect of Replication, $F_{(1,28)}=9.23$ (responding was higher in Replication 2), but no interactions with Replication, $F \mathrm{~s}_{(1,28)}<1$. There was no effect of Interval, $F_{(1,28)}=1.67$. Simple effects tests isolating each group confirmed a main effect of Block in Group Immediate, $F_{(1,14)}=20.66$, but not in Group Delayed, $F_{(1,14)}<1$, indicating retention of extinction in the latter group only. Group Immediate also responded more than Group Delayed when the first four-trial block of the test was isolated, $F_{(1,28)}=8.72$. A parallel $2 \times 2 \times 2$ ANOVA on the pre-CS data confirmed (as suggested by the figure) that the rats showed a similar pattern of responding during the pre-CS period. There was a main effect of Block and a Block $\times$ Interval interaction, $F \mathrm{~s}_{(1,28)} \geq 7.14$. No other main effects or interactions were reli-

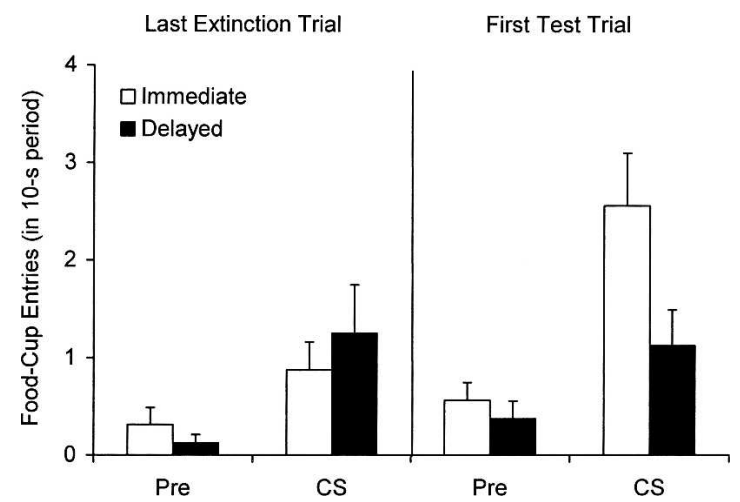

Figure 5. Mean number of food-cup entries ( \pm SE) during the 10-s CS and the equivalent 10-s period before the CS on the last extinction trial (left) and the first test trial (right) in Experiment 4.

able, $F \mathrm{~s}_{(1,28)} \leq 3.78$. When the first four-trial block of the test was isolated, there was again higher pre-CS responding after immediate than delayed extinction, $F_{(1,28)}=4.08, P=0.053$. Thus, when we examined responding to either the CS or the context (pre-CS period), there was more recovery of responding over time following immediate rather than delayed extinction.

One potential issue is that the changes in pre-CS responding might complicate interpretation of responding in the CS. Was there a change in responding to the CS over and above the effect that was apparent in the presence of the context (the pre-CS period)? The answer appears to be "yes." As depicted in Figure 5, when only the last extinction trial and the first test trial (rather than four-trial blocks) were isolated, neither group exhibited a change in pre-CS responding over the two trials. A 2 (Interval) $\times 2$ (Replication) $\times 2$ (Trial) ANOVA on the pre-CS data confirmed no main effects or interactions, $F \mathrm{~s} \leq 2.09$. When CS responding from these two trials was analyzed in a parallel ANOVA, however, there was a main effect of Trial, $F_{(1,28)}=4.12$, $P=0.052$, and importantly a Trial $\times$ Interval interaction, $F_{(1,28)}=5.54$. There was also a main effect of Replication, $F_{(1,28)}=5.39$ (higher responding in Replication 2), but no effect of Interval or other interactions, $F \mathrm{~s}_{(1,28)} \leq 2.90$. Simple effects tests isolating each group further confirmed a main effect of Trial in Group Immediate, $F_{(1,14)}=12.92$, but not in Group Delayed, $F_{(1,14)}<1$. Because pre-CS responding did not change over these trials, the different patterns of CS responding cannot be explained by changes in responding to the context. Thus, immediate extinction did result in significant spontaneous recovery of responding to the CS, whereas delayed extinction did not.

The results were thus similar to the CER experiments. Immediate extinction caused a faster loss of food-cup responding, and more spontaneous recovery, than delayed extinction. ${ }^{3}$ Overall, the present experiments suggest that the effects of immediate and delayed extinction are qualitatively similar across these two aversive and appetitive-conditioning preparations.

\section{Experiment 5: Another test for the role of contextual mismatch}

As in fear conditioning, the presence and then absence of a conditioning session immediately before extinction and testing causes a contextual mismatch that could explain the lack of durability of immediate extinction. Because there is no way of knowing whether this sort of context in appetitive conditioning is more or less important than in fear conditioning, we tested for

${ }^{3} \mathrm{~A}$ control experiment also found more spontaneous recovery following immediate than delayed extinction when the conditioning-to-test interval was controlled (A.M. Woods, unpubl.). See Footnote 2. 
the role of contextual mismatch again using the tactic we had used in fear conditioning (Experiment 3, Fig. 3). Four groups received conditioning with the tone CS (as in Experiment 4) and then delayed extinction. Half received an extra conditioning session with a different CS (the termination of the houselights) immediately before extinction. An orthogonal half received a similar conditioning session immediately before the test session. As before, groups that experienced the similar presence or absence of a conditioning session immediately before extinction and testing should show little recovery of responding during testing, whereas groups that experienced a mismatch in the experience immediately before extinction and testing should show recovery of responding.

The results, shown in Figure 6, again provided no evidence to confirm the contextual mismatch account. As before, all groups acquired food-cup responding to the CS. A 2 (Ext) $\times 2$ (Test) $\times 10$ (Block) ANOVA on CS responding over the four-trial blocks of conditioning confirmed a main effect of Block, $F_{(9,216)}=18.49$. No other main effects or interactions were reliable, $F s<1$. A parallel ANOVA on the pre-CS data did not reveal any main effects or interactions, $F \mathrm{~s} \leq 1.62$.

As shown in the middle of the upper panel, the loss of foodcup responding to the tone was slightly faster when delayed extinction began $10 \mathrm{~min}$ after a conditioning session with the light off. A 2 (Ext) $\times 2$ (Test) $\times 5$ (Block) ANOVA on CS responding during the five four-trial blocks from this session revealed a main effect of Block, $F_{(4,96)}=10.49$, but the effect of Extinction treat-
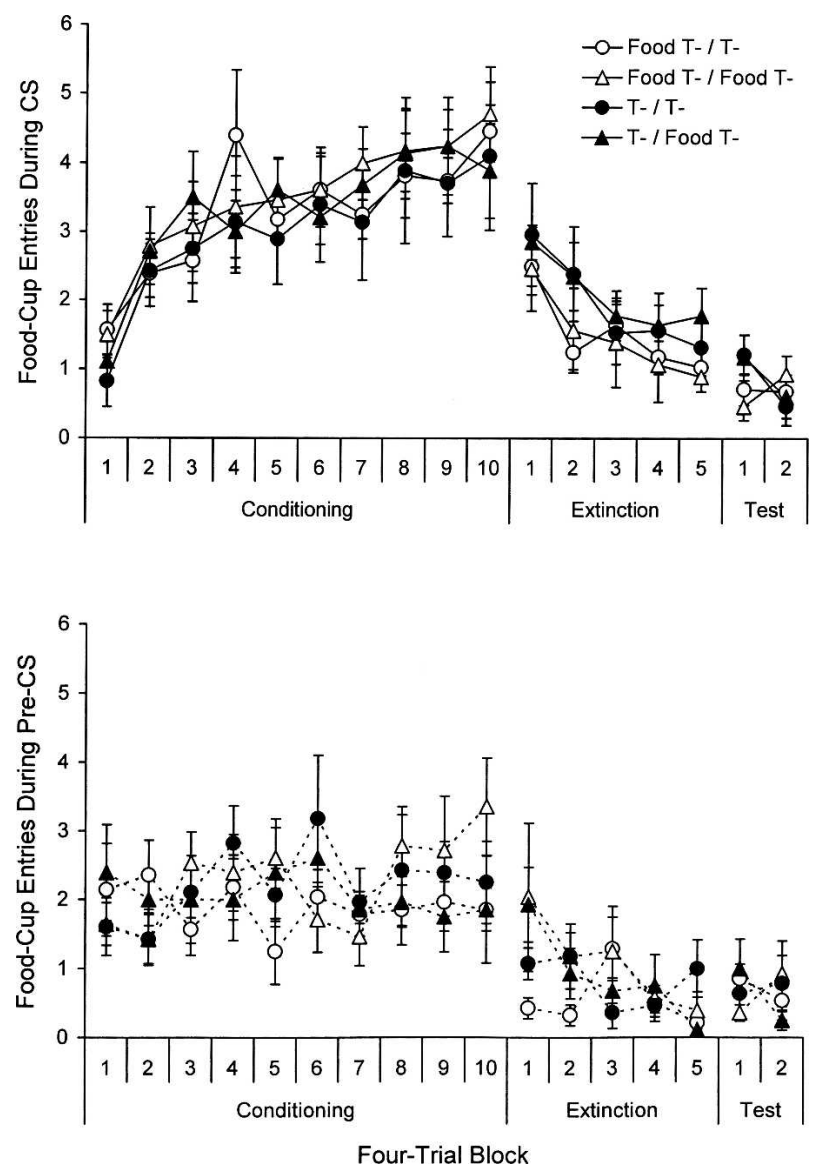

Figure 6. (Top) Mean number of food-cup entries ( $\pm \mathrm{SE}$ ) during the 10 -s CS and (bottom) the equivalent 10-s period before the CS over four-trial blocks from the conditioning session in Context A and the extinction and test sessions in Context $B$ in Experiment 5. ment did not reach significance, $F_{(1,24)}=2.36, P=0.14$. There was no effect of Test treatment and no interactions, $F \mathrm{~s}<1$. An additional ANOVA on the last block again revealed no effect of Test treatment or an interaction, $F \mathrm{~s}_{(1,24)}<1$, although the effect of Extinction treatment approached significance here, $F_{(1,24)}=3.21, P=0.086$. A parallel $2 \times 2 \times 5$ ANOVA on the preCS data revealed a main effect of Block and a Block $\times$ Test treatment interaction, $F s_{(4,96)} \geq 2.99$. As shown in the middle of the lower panel, this is likely because two groups in the food test condition, which is a dummy variable at this point, inexplicably showed higher pre-CS responding than the other two groups on the first four-trial block. There were no other main effects or interactions, $F \mathrm{~s} \leq 1.77$. An additional ANOVA examining pre-CS rates on the first four-trial block revealed no effect of extinction treatment, $F_{(1,24)}<1$.

The test data are shown on the right side of the upper panel of the figure. There was no effect of contextual mismatch. A 2 $($ Ext) $\times 2$ (Test) $\times 2$ (Block) ANOVA comparing CS responding on the last four-trial block of extinction and the first four-trial block of the test revealed only a main effect of Extinction treatment, $F_{(1,24)}=8.16$, due to a continuation of higher responding across the blocks in the normal delayed extinction groups (Groups T-/T- and T-/Food T-). No other main effects or interactions reached significance, $F \mathrm{~s}_{(1,24)} \leq 2.92$. A between-groups ANOVA isolating responding on the first four-trial block of testing also revealed a mean effect of Extinction treatment, $F_{(1,24)}=5.16$, though again this is not due to differences in the amount of recovery but rather to differences in the amount of extinction. An analogous $2 \times 2 \times 2$ ANOVA on the pre-CS data revealed a three-way interaction, $F_{(1,24)}=8.68$. Groups that experienced the same emotional context before extinction and testing (Food T-/Food T- and T-/T-) did not exhibit a change in preCS responding across the blocks, whereas groups that experienced a change in the emotional context (Food T-/T- and T-/Food T-) exhibited a slight increase. There were no other main effects or interactions, $F \mathrm{~s}_{(1,24)} \leq 3.05$. Isolating pre-CS rates on the first four-trial test block revealed no group differences, $F \mathrm{~s}_{(1,24)} \leq 2.14$. (There was no change in the pattern of test results when CS and pre-CS responding was examined over individual trials; thus, further analyses are not included.)

In the end, the results with the appetitive-conditioning procedure were consistent with those from the CER procedure. Immediate extinction caused a less durable decrease in responding than delayed extinction. And we did not confirm that this effect was due to a mismatch between the conditions present immediately before extinction and testing.

\section{Discussion}

The results of the present experiments were consistent in showing that immediate extinction did not erase the original learning, but instead led to an even greater return of original responding than delayed extinction (cf. Myers et al. 2006). This result appears to be general across both our fear-conditioning (Experiments 1 and 2) and appetitive-conditioning (Experiment 4) preparations, which likely involve different neurobiological substrates.

The findings are not consistent with the idea that immediate extinction erases or depotentiates the original learning. In both of the present conditioning preparations, immediate extinction led to more recovery of responding $24 \mathrm{~h}$ later. In Experiment 1, it also led to a renewal effect that was at least as strong as that observed following delayed extinction. As noted above, the present experiments extend Maren and Chang's (2006) results to a different fear-conditioning preparation (CER rather than freezing) as well as to a popular method of appetitive con- 
ditioning. They also extend Rescorla's (2004b) previous results by using an appetitive procedure that corresponded more closely to the number of sessions, session lengths, and intersession intervals used in the fear-conditioning experiments (Experiments 1-3) (Myers et al. 2006). The results show strong recovery of an appetitive response after a single conditioning session that was similar in duration to the one used in fear conditioning and after extinction that began within minutes of conditioning. The present results, along with the other studies, may begin to suggest that the interference with relapse effects observed after immediate extinction by Myers et al. (2006) may be relatively unique. Although the studies by Myers et al. (2006) are unique among rat studies in employing the fear-potentiated startle preparation, the fact that Alvarez et al. (2007) found renewal of potentiated startle in humans following immediate extinction suggests that the startle preparation may not be unusually sensitive to erasure effects. At this point in time, the reason for the uniqueness of the Myers et al. (2006) results is not clear.

The present findings also begin to make progress at explaining the stronger recovery seen after immediate extinction. First, Experiments 3 and 5 tested the idea that stronger recovery occurred because of a mismatch between the conditions that preceded immediate extinction and then testing. In both the CER and appetitive preparation, when a conditioning session with a different CS was factorially inserted before delayed extinction and/or testing, there was no effect of mismatch on responding during the final test. Thus, the results did not confirm the contextual mismatch hypothesis. Second, the results do not support the possibility that a high level of fear around the time of immediate extinction, rather than the brief conditioning-extinction interval on its own, causes strong recovery after immediate extinction (Maren and Chang 2006). As noted above, the incubation of responding observed during delayed extinction in Experiments 1-3, which was consistent with earlier observations in the CER preparation (McMichael 1966; Randich and Rescorla 1981), meant that the higher fear was evident during delayed rather than immediate extinction (see also Schiller et al. 2008). In addition, Experiment 4 also found stronger recovery after immediate extinction in an appetitive preparation, where level of fear was not an issue. Thus, although Maren and Chang (2006), like us, found stronger fear recovery after immediate extinction, the fact that the same outcome can occur with higher or lower levels of fear during immediate extinction suggests that the level of fear during extinction is not the controlling factor. Of course, this does not necessarily mean that when higher fear is evident during extinction (as in Maren and Chang's experiments), it does not play some role in influencing the learning and/or retention of extinction.

Learning theories provide at least three additional accounts of the stronger recovery after immediate extinction. First, a high level of conditioned responding during extinction might allow for better extinction learning, perhaps because it allows for the development of more inhibition of the response (Rescorla 2001; see Bouton and Woods 2008, for a review). On this account, delayed extinction might have caused more durable extinction responding $24 \mathrm{~h}$ later in the present experiments because the animals had learned more inhibition of the response. Although data from the present experiments might appear consistent with this account, the Maren and Chang (2006) results just described are clearly not. Thus, strong recovery after extinction appears to occur whether responding is higher or lower during delayed extinction. Other results have been critical of the response inhibition hypothesis (Rescorla 2006; see Bouton and Woods 2008, for further evaluation).

A second possibility is based on Wagner's SOP ("sometimes opponent process") model of conditioning (Wagner 1981; Wag- ner and Brandon 1989, 2001), which has been successful at explaining a broad range of conditioning phenomena. According to this theory, presentations of the CS and US activate corresponding memory nodes to a highly active state called A1. From A1, the nodes quickly decay to a secondarily active state called A2, where they stay longer but eventually decay to an inactive state. Importantly, the activation level of a node cannot move from A2 to A1 without first decaying to the inactive state. For the CS and US to become associated during conditioning, both nodes must be in A1 at the same time, which occurs when the two stimuli are presented close together in time. However, if a node happens to be in the $\mathrm{A} 2$ state at the time of a conditioning trial, conditioning can be less effective, because the node cannot be activated from the $\mathrm{A} 2$ to the A1 state.

Given the above, SOP might explain the present effects of immediate extinction in the following manner. When extinction begins very soon after conditioning, the CS node (activated during conditioning trials) might still be in $\mathrm{A} 2$, rather than the inactive state, at the start of extinction. If this is so, then the CS cannot be activated to $\mathrm{A} 1$, and this would reduce the ability to learn about the CS during extinction. Further, because the CS node is not focally active, it would not elicit as much conditioned responding. These two predictions are respectively consistent with the weaker durability of immediate extinction (which would result from less successful extinction learning) and a faster loss of responding observed in immediate extinction. One problem for this explanation, however, is that previous experiments in this laboratory suggest that similar CSs decay from A2 to the inactive state within $4 \mathrm{~min}$ after a CS presentation (Bouton and Sunsay 2003; Sunsay et al. 2004; Moody et al. 2006). The 10-min interval between conditioning and immediate extinction lies outside this window of time. Another question is raised by Experiments 3 and 5, which revealed that an extra conditioning session with a different CS 10 min before the start of delayed extinction similarly led to a more rapid short-term decline in conditioned responding. Because the target CS did not occur immediately before the extinction session, it could not have been primed in $\mathrm{A} 2$ at the start of extinction and thus could not cause this performance effect, leaving another explanation of the rapid loss of responding necessary.

It is also possible that the US node would be in A2 at the start of immediate extinction for the same reason. Unfortunately, if anything, this possibility would potentially facilitate, rather than reduce, long-term inhibitory learning during extinction, because SOP assumes that (inhibitory) extinction learning occurs when the CS is in A1 at the same time the US node is in A2. On the other hand, it appears, once again, that any activation of the node probably decayed to the inactive state before immediate extinction: In Experiments 3 and 5, the US node should have equivalently been in the A2 state when the preceding conditioning session occurred with the different CS, yet this had no demonstrable impact on extinction learning as assessed by performance during the retention tests. Overall, it does not seem likely that mechanisms provided by SOP can account for the present results.

A third type of approach is also possible. The strong recovery of responding after immediate extinction might be consistent with the idea that memory traces of both conditioning and extinction always persist after extinction, and that performance during subsequent testing is governed by the extent to which each is weighted or retrieved. For example, according to the "temporal weighting rule" (e.g., Devenport et al. 1997; Devenport 1998), responding during a spontaneous recovery test will be a function of both the time since extinction and the time since conditioning. When extinction is relatively recent (as when testing occurs when extinction has been delayed), then extinction 
responding may prevail during the test. When extinction is not relatively recent (as when extinction followed conditioning immediately and then time was allowed to elapse), then conditioned responding will prevail, because the original learning contributes relatively more to performance. Alternatively, the results might be consistent with an account of spontaneous recovery, which holds that spontaneous recovery is a renewal effect that occurs because of a change in the temporal context (e.g., Bouton 1993; Bouton and García-Gutiérrez 2006). More specifically, as time elapses, hypothetical contextual stimuli might change. The effects of any retention interval would thus depend on the similarity of the background stimuli present at times 1 and 2 . Interestingly, in such a scheme, early stimulus changes within an interval would presumably occur more rapidly than later stimulus changes, because short intervals are timed more accurately than longer ones (e.g., Gibbon 1991). Thus, if the "clock" were to start at the time of conditioning, then there would be more spontaneous recovery $24 \mathrm{~h}$ after immediate (early) than delayed (late) extinction, because there would be more substantial contextual change during the retention interval.

Whichever account proves to be more accurate, the present results make it clear that immediate extinction in the CER and magazine entry preparations does not erase the original learning, and indeed allows a stronger recovery of conditioned responding during a subsequent spontaneous recovery test.

\section{Materials and Methods}

\section{Subjects}

Female Wistar rats (Charles River, Quebec, Canada) ranging in age from 75 to $90 \mathrm{~d}$ and initially weighing 200-300 g were used. The rats were housed individually in suspended stainless steel cages in a colony room. The rats were food-deprived and maintained at $80 \%$ of their free-feeding weights beginning a week before the experiments. Water was available ad libitum.

\section{Apparatus}

All sessions occurred in two sets of four Skinner boxes (Med Associates) located in separate rooms. The two sets of boxes contained distinct contextual cues and were used as two different, counterbalanced contexts (denoted as Context A and B). Boxes from both sets measured $31.75 \times 24.13 \times 29.21 \mathrm{~cm}(\mathrm{l} \times \mathrm{w} \times \mathrm{h})$ and were housed in sound-attenuation chambers. The front and back walls were brushed aluminum; the sidewalls and ceiling were clear acrylic plastic. The rats entered the box through a door in the right wall. A $5.08 \times 5.08 \mathrm{~cm}$ recessed food cup was centered in the front wall and positioned near floor level. A thin, flat $4.8 \mathrm{~cm}$ stainless steel lever protruded $1.9 \mathrm{~cm}$ from the front wall and was positioned $6.2 \mathrm{~cm}$ above the grid floor and located to either the left or the right of the food cup, depending on the context.

In one set of boxes, the floor consisted of stainless steel grids, $0.48 \mathrm{~cm}$ in diameter, spaced $3.81 \mathrm{~cm}$ center-to-center and mounted parallel to the front wall. The ceiling and left sidewall had black horizontal stripes, $3.81-\mathrm{cm}$ wide and spaced $3.81 \mathrm{~cm}$ apart. To create a distinctive odor, a dish containing $\sim 10 \mathrm{~mL}$ of a $2 \%$ (vol/vol) anise solution (McCormick) was placed outside the front wall of each box. In the other set of boxes, the floor consisted of alternating stainless steel grids with different diameters $(0.48$ and $1.27 \mathrm{~cm})$, spaced $1.59 \mathrm{~cm}$ center-to-center. The ceiling and left sidewall were covered with rows of dark dots $(1.9 \mathrm{~cm}$ in diameter) that were separated by $\sim 1.27 \mathrm{~cm}$. To create a distinctive odor, a dish containing $\sim 10 \mathrm{~mL}$ of a $4 \%$ (vol/vol) coconut solution (McCormick) was placed outside the front wall of each box.

In both sets of boxes, ventilation fans provided background noise of $\sim 60 \mathrm{~dB}$. Illumination was provided by two $7.5-\mathrm{W}$ clear incandescent bulbs mounted to the ceiling of each soundattenuation chamber. In the fear-conditioning experiments, the target CS was a light-off cue that was created by terminating the houselights to produce darkness. The CS duration was $60 \mathrm{~s}$. The US was a $0.5-\mathrm{s}, 1-\mathrm{mA}$ foot shock. The reinforcer for the baseline lever-press response was one 45-mg food pellet (Purina Test Diet). In the appetitive-conditioning experiments, the target CS was the $3000-\mathrm{Hz}, 80-\mathrm{dB}$ tone presented for $10 \mathrm{~s}$. The US was two $45-\mathrm{mg}$ food pellets delivered $0.2 \mathrm{~s}$ apart into the food cup. Photocells mounted in the food cups, just behind the plane of the wall of the Skinner box, detected the rats' entries into the food cup. Computer equipment in a separate room controlled the apparatus and data collection. The experiments were run during the light portion of a 16:8-h light-dark cycle.

\section{Procedure for fear-conditioning experiments (Experiments 1-3)}

\section{Baseline training}

For baseline training, there were six daily 84-min sessions of lever pressing. The rats were initially reinforced on a continuous schedule of reinforcement until 35-45 presses were emitted, and were then switched to a fixed-ratio, FR-7, schedule until approximately five pellets were earned. The rats were finally placed on a variable-interval (VI) 90-s reinforcement schedule (interval range $=15-165 \mathrm{~s}$ ). Responding on the VI-90 s schedule was used throughout the remainder of the experiment and provided the baseline level from which suppression (i.e., fear) was measured.

Each rat received lever-press training in a box from both experimental contexts (A and $\mathrm{B})$. Half the sessions occurred in Context A (days 1, 2, and 6), and the other half occurred in Context B (days 3, 4, and 5). If a rat did not press the lever independently by the end of the second session, then it received an extra training session in Context A on the same day. At the end of baseline training, groups were matched based on the amount of lever pressing emitted during each session and assigned to either an immediate- or delayed-extinction condition.

\section{Conditioning}

Following baseline training, there was one 84-min session of fear conditioning in Context $\mathrm{A}$. The session involved four trials during which the 60-s light-off CS was paired with the foot shock US. The US occurred upon offset of the CS. The CS-US pairings were separated by a 20 -min average $( \pm 25 \%)$ intertrial interval (ITI).

\section{Extinction and testing}

In Experiment 1, there was one 120-min session of extinction in Context B. The session involved 16 presentations of the light off, without shock, at an average ITI of $6.5 \mathrm{~min}$. The first CS-alone trial occurred at minute nine. For half the rats (Immediate groups), the extinction session began $10 \mathrm{~min}$ after conditioning. Immediately after the last conditioning trial in Context $\mathrm{A}$, these rats were transported to the home cages and placed there for five minutes before being transported to Context $\mathrm{B}$ for extinction. For the remaining rats (Delayed groups), the extinction session began $24 \mathrm{~h}$ after conditioning. These rats were placed in the home cages during the 24-h interval between sessions. Extinction was conducted in Context $\mathrm{B}$ because doing so helped maintain the baseline lever-press response after fear conditioning. Fear conditioning generally causes a decrease in baseline responding, but moving the rats to a different context after conditioning alleviates this problem.

Following extinction, the rats in each extinction condition were matched on suppression exhibited during extinction and assigned to Groups Immediate $\mathrm{ABB}$, Immediate $\mathrm{ABA}$, Delayed $\mathrm{ABB}$, and Delayed $\mathrm{ABA}$ based on the conditioning-extinction interval and the testing context. Twenty-four hours after extinction, there was one 84-min test to assess the retention of extinction performance. The session involved four presentations of the light off, without shock, at an average ITI of $20 \mathrm{~min}$. The first trial occurred at minute 25 . During the test, half the rats from each extinction condition were placed in the extinction context (B) and tested for spontaneous recovery of fear to the light off (Groups Immediate ABB and Delayed ABB). The other rats from each condition were returned to the conditioning context (A) 
and tested for renewal of fear to the light off (Groups Immediate $\mathrm{ABA}$ and Delayed $\mathrm{ABA}$ ).

In Experiment 2, there were only two groups, Immediate and Delayed. In this case, the extinction session (which began 10 min or $24 \mathrm{~h}$ after the conclusion of conditioning), involved 32, rather than 16, presentations of the CS without shock. Although the number of extinction trials was doubled, the duration of the session remained $120 \mathrm{~min}$; to accomplish this, the average ITI was shortened to $2.75 \mathrm{~min}$. The first CS still occurred at minute nine. Testing occurred in Context B $24 \mathrm{~h}$ after extinction. As before, there were 4 test presentations of the CS, without shock, at a 20 -min average ITI in an 84-min session.

In Experiment 3, the four groups received one 120-min session of extinction in Context B $24 \mathrm{~h}$ after conditioning. As in Experiment 1, there were 16 presentations of the target light-off CS without shock. Half the rats received no treatment immediately prior to the extinction session. The other half received a session of fear conditioning with a 60-s tone CS ending 10 min before the extinction. (Like conditioning with the light-off CS, conditioning with the tone again involved an 84-min session in Context A with four tone-shock pairings spaced by a variable 20-min ITI.) After the last conditioning trial, these rats were returned to the home cages and placed there for five minutes before being transported to Context B for extinction.

Twenty-four hours after extinction, the rats were returned to Context $\mathrm{B}$ and tested for spontaneous recovery of suppression to the target light-off CS following the usual procedure. Half the rats from each of the extinction conditions described above received the usual treatment. For the other half, there was a four-trial conditioning session with the tone CS. As before, these rats were returned to the home cage between sessions; the interval between the end of tone conditioning and testing was $10 \mathrm{~min}$.

\section{Dependent measure}

The computer recorded the number of lever presses for each rat during the 60-s CS as well as during the 60-s period immediately preceding the CS (the "pre-CS" period). These data were used to calculate the standard suppression ratio (e.g., Annau and Kamin 1961) defined as $C /(C+P)$, where $C$ is the number of responses made during the CS, and $P$ is the number of responses made during the equivalent pre-CS period. A score of 0.5 denotes no lever-press suppression during the CS (i.e., no fear), whereas a score of 0 denotes complete suppression of responding during the CS (i.e., substantial conditioned fear).

\section{Procedure for appetitive-conditioning experiments (Experiments 4 and 5)}

\section{Magazine training}

Before conditioning, the rats were trained to eat food pellets when they were delivered to the food cup. Thirty pellets, spaced by $40 \mathrm{~s}$ on average (ranging from 5 to $75 \mathrm{~s}$ ), were delivered (not contingent on behavior) during a 20 -min session. The rats received one session in Context A and one session in Context B the next day.

\section{Conditioning}

On the day after magazine training, there was one 90-min session of appetitive conditioning in Context A. The session involved 40 trials in which the 10-s tone CS was paired with the food US. Delivery of the US coincided with offset of the CS. The average ITI was $2.08 \mathrm{~min}$.

\section{Extinction and testing}

In Experiment 4, there was one 45-min session of extinction in Context B. The session contained 20 presentations of the tone, without food, spaced by a 2.08 -min average ITI. The first CSalone trial occurred at minute 2.08. The extinction session began either $10 \mathrm{~min}$ (Group Immediate) or $24 \mathrm{~h}$ (Group Delayed) after conditioning. As before, the rats were placed in the home cages during the interval between sessions. Conducting extinction in Context B (rather than A) followed the design used in the fear- conditioning experiments. Twenty-four hours after extinction, the rats were returned to Context $\mathrm{B}$ and tested for spontaneous recovery of the food cup responding to the tone. The session was $18 \mathrm{~min}$ in duration and involved eight presentations of the tone, without food, spaced by a 2.08 -min average ITI. The first trial occurred at minute 2.08 .

In Experiment 5, all four groups received extinction with the delayed procedure used in Experiment 4 . Half the rats received a treatment identical to those in Experiment 4. The other half received a session of conditioning with the other CS, a 10-s light off, immediately before extinction. Like conditioning with the tone, conditioning with the light off involved a 90-min session in Context A with 40 light-off and food pairings spaced by a 2.08-min average ITI. After the last conditioning trial, these rats were returned to the home cages and placed there for $5 \mathrm{~min}$ before being transported to Context B for extinction. Twentyfour hours after extinction, the rats were returned to Context B and tested for spontaneous recovery to the tone following Experiment 4's procedure. Half the rats from each extinction condition were tested as usual. The other half of the rats received a 40 -trial conditioning session with the light off in Context A. As usual, these rats were returned to the home cages and held for 5 min between sessions.

\section{Dependent measure}

The computer recorded the number of food-cup entries made by each rat during the 10 -s CS and 10-s period immediately preceding the CS ("pre-CS"). The number of food-cup entries during the CS is widely used as a measure of appetitive conditioning. The number of food-cup entries made during the pre-CS period, which occurred in the presence of the context, provides a possible measure of responding to the context (rather than the CS).

\section{Data treatment and analysis}

All statistical analyses utilized analysis of variance (ANOVA). In the fear-conditioning experiments, suppression ratios and pre-CS data were submitted to identical ANOVAs. In the appetitive experiments, food-cup responding during the CS and pre-CS periods were likewise submitted to identical ANOVAs. Throughout, a rejection criterion of $P<0.05$ was used.

All experiments began with eight subjects per group. To increase statistical power, Experiments 3 and 4 used 16 per group (the experiments were run in two replications with $n=8$ ). The designs required that rats learn both conditioning and extinction in single sessions. In the fear-conditioning experiments, $14 \%$ of the rats, distributed evenly over groups, failed to show evidence of extinction during the single extinction session. Test analyses therefore excluded rats that failed to achieve extinction (defined as suppression ratios above at least 0.15 on the last 4-trial block of extinction; the mean ratio for excluded rats was 0.06). This resulted in final $n s$ of 7, 8, 6, and 7 for Groups Immediate ABB, Immediate ABA, Delayed ABB, and Delayed ABA in Experiment 1 ; 8 and 7 for Groups Immediate and Delayed in Experiment 2; and $12,12,13$, and 12, for groups L-/L-, Shock L-/L-, L-/Shock L-, and Shock L-/Shock L- in Experiment 3 (four additional rats were excluded for failure to lever-press during the extinction session). In the appetitive experiments, no rat failed to extinguish. However, in Experiment 5, four rats had to be excluded for failing to show evidence of conditioning, with CS responding of $\leq 1.25$ (mean $=0.69$ ) on the last four-trial block of conditioning (leaving $n \mathrm{~s}=7$ ).

\section{Acknowledgments}

This research was supported by grant RO1 MH64827 from the National Institute of Mental Health (to M.E.B.). The experiments are part of a dissertation to be submitted by A.M.W. to the University of Vermont in partial fulfillment of the requirements of a Ph.D. degree. We thank Drina Vurbic for her comments on the manuscript. 


\section{References}

Alvarez, R.P., Johnson, L., and Grillon, C. 2007. Contextual-specificity of short-delay extinction in humans: Renewal of fear-potentiated startle in a virtual environment. Learn. Mem. 14: 247-253.

Annau, Z. and Kamin, L.J. 1961. The conditioned emotional response as a function of intensity of the US. J. Comp. Physiol. Psychol. 54: 428-432.

Aroniadou-Anderjaska, V., Post, R.M., Rogawski, M.A., and Li, H. 2001. Input-specific LTP and depotentiation in the basolateral amygdala. Neuroreport 12: 635-640.

Barlow, D.H. 1988. Anxiety and its disorders: The nature and treatment of anxiety and panic. Guilford Press, New York.

Bouton, M.E. 1984. Differential control by context in the inflation and reinstatement paradigms. J. Exp. Psychol. Anim. Behav. Process. 10: 56-74.

Bouton, M.E. 1988. Context and ambiguity in the extinction of emotional learning: Implications for exposure therapy. Behav. Res. Ther. 26: 137-149.

Bouton, M.E. 1993. Context, time, and memory retrieval in the interference paradigms of Pavlovian learning. Psychol. Bull. 114: 80-99.

Bouton, M.E. 2002. Context, ambiguity, and unlearning: Sources of relapse after behavioral extinction. Biol. Psychiatry 52: 976-986.

Bouton, M.E. 2004. Context and behavioral processes in extinction Learn. Mem. 11: 485-494.

Bouton, M.E. and Bolles, R.C. 1979a. Contextual control of the extinction of conditioned fear. Learn. Motiv. 10: 445-466.

Bouton, M.E. and Bolles, R.C. 1979b. Role of conditioned contextual stimuli in reinstatement of extinguished fear. J. Exp. Psychol. Anim. Behav. Process. 5: 368-378.

Bouton, M.E. and García-Gutiérrez, A. 2006. Intertrial interval as a contextual stimulus. Behav. Processes 71: 307-317.

Bouton, M.E. and King, D.A. 1983. Contextual control of the extinction of conditioned fear: Tests for the associative value of the context. $J$. Exp. Psychol. Anim. Behav. Process. 9: 248-265.

Bouton, M.E. and Sunsay, C. 2003. Importance of trials versus accumulating time across trials in partially reinforced appetitive conditioning. J. Exp. Psychol. Anim. Behav. Process. 29: 62-77.

Bouton, M.E. and Woods, A.M. 2008. Extinction: Behavioral mechanisms and their implications. In Learning and memory: A comprehensive reference (eds. J.H. Byrne, D. Sweatt, R. Menzel, H. Eichenbaum, and H. Roediger), Vol. 1, pp. 151-171. Elsevier, Oxford, UK.

Bouton, M.E., Westbrook, R.F., Corcoran, K.A., and Maren, S. 2006a. Contextual and temporal modulation of extinction: Behavioral and biological mechanisms. Biol. Psychiatry 60: 352-360.

Bouton, M.E., Woods, A.M., Moody, E.W., Sunsay, C., and García-Gutiérrez, A. 2006b. Counteracting the context-dependence of extinction: Relapse and some tests of possible methods of relapse prevention. In Fear and learning: From basic processes to clinical implications (eds. M.G. Craske, D. Hermans, and D. Vansteenwegen), pp. 175-196. American Psychological Association, Washington, DC.

Brooks, D.C. and Bouton, M.E. 1993. A retrieval cue for extinction attenuates spontaneous recovery. J. Exp. Psychol. Anim. Behav. Process. 19: 77-89.

Davis, M. and Myers, K.M. 2002. The role of glutamate and Gamma-Aminobutyric acid in fear extinction: Clinical implications for exposure therapy. Biol. Psychiatry 52: 998-1007.

Devenport, L.D. 1998. Spontaneous recovery without interference: Why remembering is adaptive. Anim. Learn. Behav. 26: 172-181.

Devenport, L., Hill, T., Wilson, M., and Ogden, E. 1997. Tracking and averaging in variable environments: A transition rule. J. Exp. Psychol. Anim. Behav. Process. 23: 450-460.

Dirikx, T., Hermans, D., Vansteenwegen, D., Baeyens, F., and Eelen, P. 2007. Reinstatement of conditioned responses in human differential fear conditioning. J. Behav. Ther. Exp. Psychiatry 38: 237-251.

Estes, W.K. and Skinner, B.F. 1941. Some quantitative properties of anxiety. J. Exp. Psychol. 29: 390-400.

Falls, W.A., Miserendino, M.J., and Davis, M. 1992. Extinction of fear-potentiated startle: Blockade by infusion of an NMDA antagonist into the amygdala. J. Neurosci. 12: 854-863.

Fanselow, M.S. 1993. Associations and memories: The role of NMDA receptors and long-term potentiation. Curr. Dir. Psychol. Sci. 2: 152-157.

Gibbon, J. 1991. Origins of scalar timing. Learn. Motiv. 22: 3-38.

Guastella, A.J., Richardson, R., Lovibond, P.F., Rapee, R.M., Gaston, J.E., Mitchell, P., and Dadds, M.R. 2008. A randomized controlled trial of D-cycloserine enhancement of exposure therapy for social anxiety disorder. Biol. Psychiatry 63: 544-549.

Harris, J.A., Jones, M.L., Bailey, G.K., and Westbrook, R.F. 2000. Contextual control over conditioned responding in an extinction paradigm. J. Exp. Psychol. Anim. Behav. Process. 26: 174-185.

Hermans, D., Dirikx, T., Vansteenwegen, D., Baeyens, F., Van den Bergh, O., and Eelen, P. 2005. Reinstatement of fear responses in human aversive conditioning. Behav. Res. Ther. 43: 533-551.

Huang, C.C., Liang, Y.C., and Hsu, K.S. 2001. Characterization of the mechanism underlying the reversal of long term potentiation by low frequency stimulation at hippocampal CA1 synapses. J. Biol. Chem. 276: $48108-48117$.

Kamin, L.J. 1969. Predictability, surprise, attention, and conditioning. In Punishment and aversive behavior (eds. B.A. Campbell and R.M. Church), pp. 279-296. Appleton-Century-Crofts, New York.

Kushner, M.G., Kim, S.W., Donahue, C., Thuras, P., Adson, D., Kotlyar, M., McCabe, J., Peterson, J., and Foa, E.B. 2007. D-cycloserine augmented exposure therapy for obsessive-compulsive disorder. Biol. Psychiatry 62: 835-838.

LaBar, K.S. and Phelps, E.A. 2005. Reinstatement of conditioned fear in humans is context dependent and impaired in amnesia. Behav. Neurosci. 119: 677-686.

Lattal, K.M. 1999. Trial and intertrial durations in Pavlovian conditioning: Issues of learning and performance. J. Exp. Psychol. Anim. Behav. Process. 25: 433-450.

Lattal, K.M. and Abel, T. 2001. Different requirements for protein synthesis in acquisition and extinction of spatial preferences and context-evoked fear. J. Neurosci. 21: 5773-5780.

Ledgerwood, L., Richardson, R., and Cranney, J. 2003. Effects of D-cycloserine on extinction of conditioned freezing. Behav. Neurosci. 117: $341-349$.

Lin, C.-H., Lee, C.-C., and Gean, P.-W. 2003a. Involvement of a calcineurin cascade in amygdala depotentiation and quenching of fear memory. Mol. Pharmacol. 63: 44-52.

Lin, C.-H., Yeh, S.-H., Lu, H.-Y., and Gean, P.-W. 2003b. The similarities and diversities of signal pathways leading to consolidation of conditioning and consolidation of extinction of fear memory. $J$. Neurosci. 23: 8310-8317.

Lin, C.-H., Lee, C.-C., Huang, Y.-C., Wang, S.-J., and Gean, P.-W. 2005. Activation of group II metabotropic glutamate receptors induces depotentiation in amygdala slices and reduces fear-potentiated startle in rats. Learn. Mem. 12: 130-137.

Lu, K.-T., Walker, D.L., and Davis, M. 2001. Mitogen-activated protein kinase cascade in the basolateral nucleus of amygdala is involved in extinction of fear-potentiated startle. J. Neurosci. 21: 1-5.

Maren, S. and Chang, C.H. 2006. Recent fear is resistant to extinction. Proc. Natl. Acad. Sci. 103: 18020-18025.

McMichael, J.S. 1966. Incubation of anxiety and instrumental behavior. J. Comp. Physiol. Psychol. 61: 208-211.

McNally, G.P. and Westbrook, R.F. 2006. A short intertrial interval facilitates acquisition of context-conditioned fear and a short retention interval facilitates its expression. J. Exp. Psychol. Anim. Behav. Process. 32: 164-172.

Milad, M.R., Orr, S.P., Pitman, R.K., and Rauch, S.L. 2005. Context modulation of memory for fear extinction in humans. Psychophysiology 42: 456-464.

Moody, E.W., Sunsay, C., and Bouton, M.E. 2006. Priming and trial spacing in extinction: Effects on extinction performance, spontaneous recovery, and reinstatement in appetitive conditioning. Q. J. Exp. Psychol. 59: 809-829.

Morris, R.W. and Bouton, M.E. 2006. Effect of unconditioned stimulus magnitude on the emergence of conditioned responding. J. Exp. Psychol. Anim. Behav. Process. 32: 371-385.

Morris, R.W. and Bouton, M.E. 2007. The effect of yohimbine on the extinction of conditioned fear: A role for context. Behav. Neurosci. 121: $501-514$

Myers, K.M. and Davis, M. 2002. Behavioral and neural analysis of extinction. Neuron 36: 567-584.

Myers, K.M., Ressler, K.J., and Davis, M. 2006. Different mechanisms of fear extinction dependent on length of time since fear acquisition. Learn. Mem. 13: 216-223.

Napier, R.M., Macrae, M., and Kehoe, E.J. 1992. Rapid reacquisition in conditioning of the rabbit's nictitating membrane response. J. Exp. Psychol. Anim. Behav. Process. 18: 182-192.

Pavlov, I.P. 1927. Conditioned reflexes (trans. G.V. Anrep). Oxford University Press, London.

Pearce, J.M. and Hall, G. 1980. A model for Pavlovian learning: Variations in the effectiveness of conditioned but not of unconditioned stimuli. Psychol. Rev. 87: 532-552.

Randich, A. and Rescorla, R.A. 1981. The effects of separate presentations of the US on conditioned suppression. Anim. Learn. Behav. 9: 56-64.

Rescorla, R.A. 1968. Probability of shock in the presence and absence of CS in fear conditioning. J. Comp. Physiol. Psychol. 66: 1-5.

Rescorla, R.A. 2001. Experimental extinction. In Handbook of contemporary learning theories (eds. R.R. Mowrer and S.B. Klein), pp. 
119-154. Erlbaum, Mahwah, NJ.

Rescorla, R.A. 2004a. Spontaneous recovery. Learn. Mem. 11: 501-509.

Rescorla, R.A. 2004b. Spontaneous recovery varies inversely with the training-extinction interval. Learn. Behav. 32: 401-408.

Rescorla, R.A. 2006. Deepened extinction from compound stimulus presentation. J. Exp. Psychol. Anim. Behav. Process. 32: 135-144.

Rescorla, R.A. and Durlach, P.J. 1987. The role of context in intertrial interval effects in autoshaping. Q. J. Exp. Psychol. Sec. B 39: 35-48.

Rescorla, R.A. and Heth, C.D. 1975. Reinstatement of fear to an extinguished conditioned stimulus. J. Exp. Psychol. Anim. Behav. process. 1: 88-96.

Rescorla, R.A. and Wagner, A.R. 1972. A theory of Pavlovian conditioning: Variations in the effectiveness of reinforcement and nonreinforcement. In Classical conditioning II: Current research and theory (eds. A.H. Black and W.F. Prokasy), pp. 64-99. Appleton-Century-Crofts, New York.

Ressler, K.J., Rothbaum, B.O., Tannenbaum, L., Anderson, P., Graap, K. Zimand, E., Hodges, L., and Davis, M. 2004. Cognitive enhancers as adjuncts to psychotherapy: Use of D-cycloserine in phobic individuals to facilitate extinction of fear. Arch. Gen. Psychiatry 61: 1136-1144.

Ricker, S.T. and Bouton, M.E. 1996. Reacquisition following extinction in appetitive conditioning. Anim. Learn. Behav. 24: 423-436.

Santini, E., Ge, H., Ren, K., Peña de Ortiz, S., and Quirk, G.J. 2004. Consolidation of fear extinction requires protein synthesis in the medial prefrontal cortex. J. Neurosci. 24: 5704-5710.

Schiller, D., Cain, C.K., Curley, N.G., Schwartz, J.S., Stern, S.A., Ledoux, J.E., and Phelps, E.A. 2008. Evidence for recovery of fear following immediate extinction in rats and humans. Learn. Mem. 15: 394-402.

Spence, K.W. and Norris, E.B. 1950. Eyelid conditioninig as a function of the intertrial interval. J. Exp. Psychol. 40: 716-720.

Stäubli, U. and Chun, D. 1996. Factors regulating the reversibility of long-term potentiation. J. Neurosci. 16: 853-860.

Sunsay, C., Stetson, L., and Bouton, M.E. 2004. Memory priming and trial spacing effects in Pavlovian learning. Learn. Behav. 32: 220-229.

Szapiro, G., Vianna, M.R., McGaugh, J.L., Medina, J.H., and Izquierdo, I. 2003. The role of NMDA glutamate receptors, PKA, MAPK, and CaMKII in the hippocampus in extinction of conditioned fear. Hippocampus 13: 53-58.
Vianna, M.R., Szapiro, G., McGaugh, J.L., Medina, J.H., and Izquierdo, I. 2001. Retrieval of memory for fear-motivated training initiates extinction requiring protein synthesis in the rat hippocampus. Proc. Natl. Acad. Sci. 98: 12251-12254.

Wagner, A.R. 1981. SOP: A model of automatic memory processing in animal behavior. In Information processing in animals: Memory mechanisms (eds. N.E. Spear and R.R. Miller), pp. 5-47. Erlbaum, Hillsdale, NJ.

Wagner, A.R. and Brandon, S.E. 1989. Evolution of a structured connectionist model of Pavlovian conditioning (AESOP). In Contemporary learning theories: Pavlovian conditioning and the status of traditional learning theory (eds. S.B. Klein and R.R. Mowrer), pp. 149-189. Erlbaum, Hillsdale, NJ.

Wagner, A.R. and Brandon, S.E. 2001. A componential theory of Pavolovian conditioning. In Handbook of contemporary learning theories (eds. R.R. Mowrer and S.B. Klein), pp. 23-64. Erlbaum, Mahway, NJ.

Walker, D.L. and Davis, M. 2002. The role of amygdala glutamate receptors in fear learning, fear-potentiated startle, and extinction. Pharmacol. Biochem. Behav. 71: 379-392.

Walker, D.L., Ressler, K.J., Lu, K.-T., and Davis, M. 2002. Facilitation of conditioned fear extinction by systemic administration or intra-amygdala infusions of D-cycloserine as assessed with fear-potentiated startle in rats. J. Neurosci. 22: 2343-2351.

Westbrook, R.F., Iordanova, M., McNally, G., Richardson, R., and Harris, J.A. 2002. Reinstatement of fear to an extinguished conditioned stimulus: Two roles for context. J. Exp. Psychol. Anim. Behav. Process. 28: $97-110$.

Whitlock, J.R., Heynen, A.J., Shuler, M.G., and Bear, M.F. 2006. Learning induces long-term potentiation in the hippocampus. Science 313: 1093-1097.

Woods, A.M. and Bouton, M.E. 2006. D-cycloserine facilitates extinction but does not eliminate renewal of the conditioned emotional response. Behav. Neurosci. 120: 1159-1162.

Received May 22, 2008; accepted in revised form October 7, 2008. 


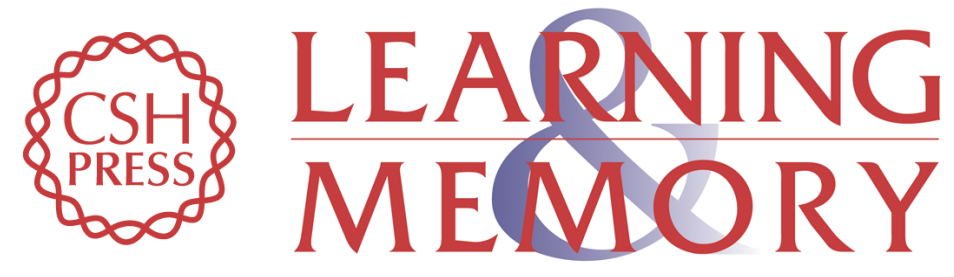

\section{Immediate extinction causes a less durable loss of performance than delayed extinction following either fear or appetitive conditioning}

Amanda M. Woods and Mark E. Bouton

Learn. Mem. 2008, 15:

Access the most recent version at doi:10.1101/lm.1078508

References This article cites 68 articles, 18 of which can be accessed free at: http://learnmem.cshlp.org/content/15/12/909.full.html\#ref-list-1

License

Email Alerting

Receive free email alerts when new articles cite this article - sign up in the box at the Service top right corner of the article or click here. 